\title{
Conflictos hídricos: lecciones para el presente
}

La atención a los conflictos hídricos presentes y futuros en todo el mundo deberá contener un compromiso moral e intelectual

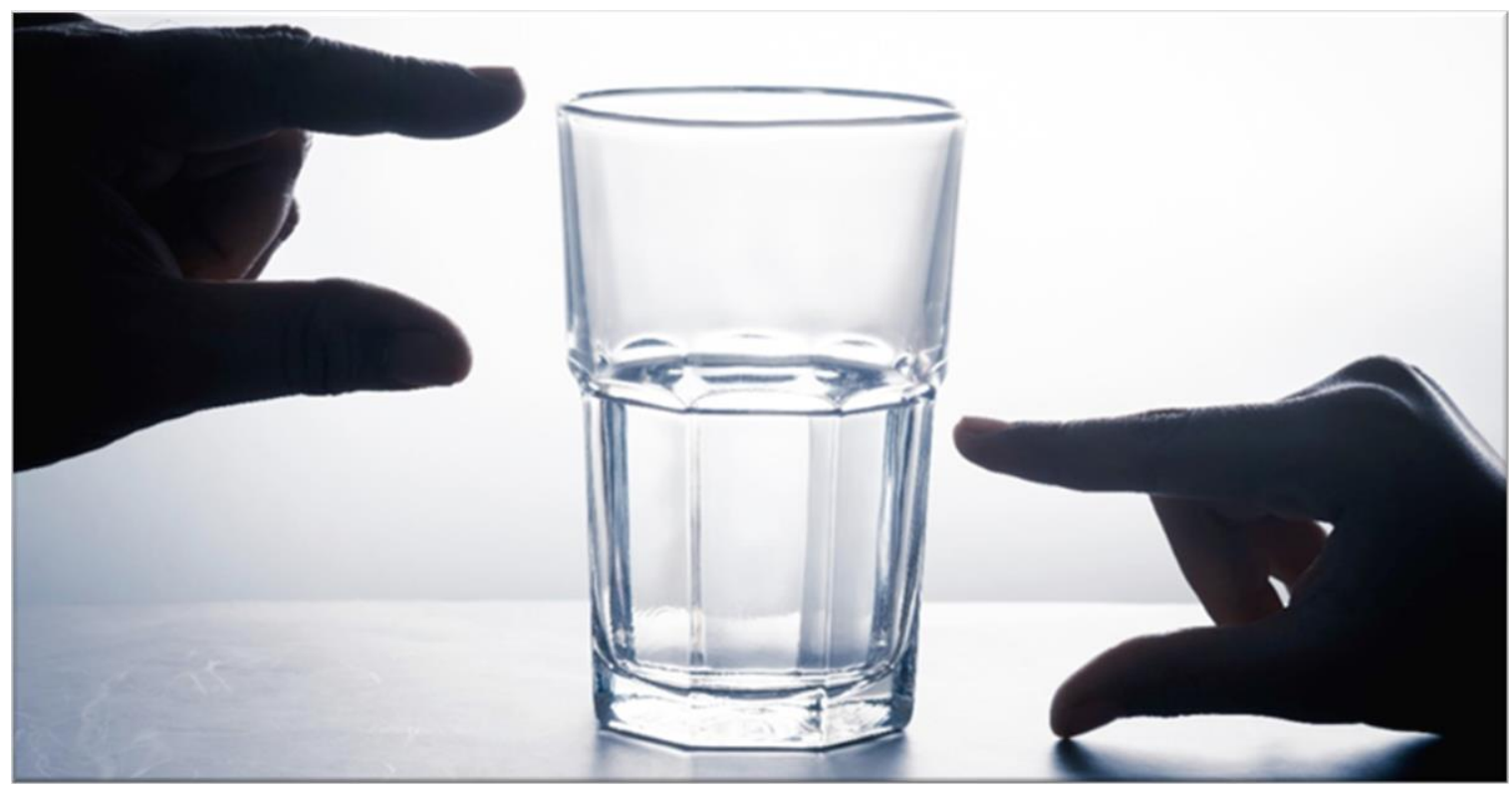

Necesitamos cambiar nuestra forma de pensar y atender los temas hídricos, con base en el mejor conocimiento disponible y la ética de nuestro quehacer en

la sociedad.

La magnitud y el número de conflictos hídricos que se están registrando en todo el mundo señalan la necesidad de utilizar el conocimiento de punta y la capacidad tecnológica y social de las instituciones de investigación para asistir a todas las personas atrapadas en conflictos hídricos.

Si bien hemos observado un avance en la atención de los problemas ambientales por parte de las agendas políticas globales - como la de las Metas del Desarrollo Sostenible de la Organización de las Naciones Unidas-, la lucha de las personas por el agua es un factor que persiste de manera cotidiana en todo el mundo. La naturaleza intratable de estos conflictos hídricos se acentúa por la manera asimétrica en la que las partes involucradas experimentan el daño. Por ejemplo, la respuesta a una de las sequías más severas en la historia de California (2012-2015) tuvo efectos igualmente asimétricos: muchos jardineros dejaron de regar sus céspedes conforme las presas se iban vaciando, pero las grandes empresas de agronegocios tuvieron acceso a fuentes de agua subterránea. Al final de cuentas se utilizó más agua durante la sequía que antes de esta, lo que dejó al sur de California con su rasgo icónico de 
PERSPECTIVAS IMTA (0)

$N^{\circ} .02,2021$

MEDIO AMBIENTE

ser un lugar en el que es posible producir almendras, mantener grandes ciudades, gloria y dinero, pero no una política sustentable.

A inicios de 2019 se registró también cierta tensión en la cuenca del río Nilo. Se consideraba que la Gran Presa del Renacimiento Etíope representaba una amenaza sobre el sustento de los agricultores y la producción de hidroelectricidad en la región aguas abajo: Egipto y Sudán. El estrés creció también en Bagdad como resultado de que Ankara y Teherán continuaban con sus esfuerzos para apropiarse del agua subterránea de acuíferos compartidos, pero dentro de su territorio. Por si fuera poco, Turquía estaba en proceso de llenado de la presa Illisu, como la pieza de cierre del proyecto del sureste de Anatolia. Otros autores argumentan que la política hídrica de Israel sobre el río Jordán les ha permitido construir una buena relación con Jordán, pero no una buena relación con los palestinos.

En México, tan solo el año pasado, fuimos testigos de conflictos hídricos en la cuenca del río Bravo por los volúmenes de agua compartidos en una cuenca por diversos usuarios.

Estas son tan solo unas facetas de la realidad de los conflictos hídricos que se están presentando en el mundo y, sin duda, constituyen un indicador de la necesidad de nuevos paradigmas para la gestión del agua, ya que es imposible continuar aceptando el gran impacto que estas tensiones generan sobre las vidas de millones de personas y ecosistemas que dependen de los flujos de agua. Estos conflictos tienen su origen en la desecación de ríos, la sobreexplotación de acuíferos y, desde luego, la falta de atención a dimensiones sociales, como la equidad y la justicia.

Estos conflictos también traen consigo lecciones que no debemos dejar de revisar y registrar. La primera es que la naturaleza intratable de los conflictos hídricos nunca se puede erradicar del todo. Las consecuencias negativas de un conflicto pueden reducirse; sin embargo, esta acción transforma al conflicto mismo en algo diferente y totalmente impredecible. Al igual que las personas y las sociedades, los ríos y la lluvia están en constante cambio. Lo mismo sucede con los conflictos hídricos, por lo que su transformación no trata sobre vencedores o perdedores, tampoco sobre la eliminación de la lucha sobre los valores y prioridades locales del agua. Ciertamente, la atención de los conflictos hídricos a través de su transformación no niega que nuevos arreglos sobre la distribución del agua generarán nuevos retos. No obstante, los esfuerzos de transformación de algo que está caduco tienen mayor probabilidad de éxito que mantenerlo para administrar un conflicto. La segunda lección, muy relacionada con esto, es que, en el caso de conflictos transfronterizos, la diplomacia del agua se conforma como una vía posible para manifestar y poner sobre la mesa de negociación los intereses nacionales de cada país involucrado. Una tercera lección que es evidente de los esfuerzos diplomáticos para la resolución de los conflictos en los ríos Nilo y Jordán es el importante papel que desempeña el poder de cada protagonista. Diversos académicos indican que no existen tratados o arreglos de distribución de agua que sean inequitativos y que favorezcan al actor menos poderoso. Existe un sinnúmero de manifestaciones visibles e invisibles de poder, cada una moldeando los acuerdos en formas específicas. En general, se observa que si lo que se busca es administrar el conflicto, en estos casos el poder tiene todo el espacio para limitar el alcance de la diplomacia, con lo que puede limitar también la generación de nuevos arreglos para la distribución del agua. Las formas más ocultas de poder moldean la forma de pensar de aquellos que interactúan con el agua; por ejemplo, utilizando un paradigma caduco y asumiéndolo como verdad, creando así una realidad que resulta de la coerción de ideas que tienden a ocultar los efectos negativos de un conflicto hídrico a aquellos actores que tendrán que hacerles frente. En este caso, la lección es doble: las asimetrías de poder deben ser reconocidas para revelar las oportunidades de mejora que no son inmediatamente aparentes, y las agendas de poder ocultas deben ser reconocidas para dar paso a una verdadera transformación del conflicto. 
PERSPECTIVAS IMTA (0)

$N^{\circ} .02,2021$

La última lección se refiere a la necesidad de superar herramientas de análisis imprecisas y poco confiables. La separación de los temas relativos a la justicia y equidad de los temas más técnicos relativos al agua (p. ej. hidrología, disponibilidades, etc.) invisibiliza los efectos negativos de las decisiones hídricas. Si hemos de avanzar hacia la solución de los conflictos hídricos, primero debemos entenderlos desde una perspectiva multidisciplinaria, que trascienda lo puramente técnico. Es decir, es importante conocer la naturaleza del agua y su movimiento en atmósfera, cuencas, ríos y acuíferos, pero también es importante ver la variación de este ciclo en su relación con los seres humanos en el tiempo y apreciar como cambios antropogénicos regionales derivados de la forma en que administramos el agua tienen efectos en su disponibilidad y calidad en el ámbito local.

Así, la atención a los conflictos hídricos presentes y futuros en todo el mundo deberá contener un compromiso moral e intelectual, que reconozca no solo el valor de los números generados desde las disciplinas más áridas como la ingeniería, sino que sea capaz también de reconocer la importancia de los valores intangibles asociados al agua, bajo principios de justicia y emancipación de aquellos que se han quedado atrás. Solo así podremos avanzar hacia la posibilidad de hacer del agua el elemento que habilite el desarrollo social y económico de todos, sin sesgo hacia el poder o el dinero. Esa sería la transformación del agua en México. Estamos convencidos de que es posible, pero para ello necesitamos cambiar nuestra forma de pensar y atender los temas hídricos, con base en el mejor conocimiento disponible y la ética de nuestro quehacer en la sociedad.

\section{Referencias:}

Ashour, M. A., Aly, T. E., y Abueleyon, H. M. (2019). Transboundary water resources "A comparative study": The lessons learnt to help solve the Nile basin water conflict, Limnological Review, 19(1), 3-14. doi:

https://doi.org/10.2478/limre-2019-0001.

Bernauer, T. y Böhmelt, T., 2020. International conflict and cooperation over freshwater resources. Nature

Sustainability, 3(5), pp.350-356.

Kittikhoun, A. y D. M. Staubli, 2018. Water diplomacy and conflict management in the Mekong: From rivalries to cooperation, Journal of Hydrology, Volume 567,

Páginas 654-667, https://doi.org/10.1016/j.jhydrol.2018.09.059.

L Ohlsson, 2000. Water conflicts and social resource scarcity,

Physics and Chemistry of the Earth, Part B: Hydrology, Oceans and Atmosphere, Volume 25, Issue 3, Páginas $213-$ 220, https://doi.org/10.1016/S1464-1909(00)00006-X.

Petersen-Perlman, J.D., Veilleux, J.C. y Wolf, A.T., 2017. International water conflict and cooperation: challenges and opportunities. Water International, 42(2), pp.105-120. 